Pesq. Vet. Bras. 35(9):767-774, setembro 2015 DOI: 10.1590/S0100-736X2015000900001

\title{
Determinação de cobre e outros minerais em caprinos e ovinos criados no sertão do vale do rio São Francisco, Pernambuco ${ }^{1}$
}

\author{
Salvador S. Silva Júnior ${ }^{2 *}$, Alexandre. C. Antonelli ${ }^{3}$, George W.N. Soares ${ }^{4}$, \\ Iara M.M. Gomes ${ }^{4}$ e Josemário F. Rocha Filho ${ }^{4}$
}

\begin{abstract}
Silva Júnior S.S., Antonelli A.C., Soares G.W.N., Gomes I.M.M. \& Rocha Filho J.F. 2015. [Determination of copper and other minerals in goats and sheep of the San Francisco river valley in Pernambuco, Brazil.] Determinação de cobre e outros minerais em caprinos e ovinos criados no sertão do vale do Rio São Francisco, Pernambuco. Pesquisa Veterinária Brasileira 35(9):767-774. Departamento de Clínica Médica e Cirúrgica de Grandes Animais, Universidade Federal do Vale do São Francisco, Rodovia BR-407 Km 12, Lote 543, Projeto de Irrigação Senador Nilo Coelho s/n, C1, Petrolina, PE 56300-990, Brazil. E-mail: salvador.veterinario@hotmail.com

For the determination of copper concentration and its antagonists, 160 serum and liver samples were used, from goat and sheep sent to the municipal slaughterhouse of Petrolina. The samples were correlated with the same animal, in order to prevent errors in data collection. Serum ceruloplasmin activity was determined by colorimetric method. For determination of minerals, the samples were diluted six to twenty times with Milli- $Q$ water. For determining concentrations of mineral elements in the liver, the samples were digested until achieving a solution that maintained the initial sample and minerals totally liquid, without the presence of solid particles which could clog the capillary suction of the spectrometer and prevent reading of samples. The concentrations of copper, molybdenum, iron and zinc were determined by optical emission spectrometry (ICP). Thus, the experiment was conducted to determine the occurrence and distribution of copper deficiency in the San Francisco valley of Pernambuco. No copper deficiency was revealed in this region of the state of Pernambuco, when the mean levels of hepatic copper were evaluated. Zinc levels were within a normal range, whereas iron levels were higher in sheep, and lower levels of molybdenum in goats. It was also found that the activity of ceruloplasmin was an indicator of serum copper.
\end{abstract}

INDEX TERMS: Ceruloplasmin, copper, mineral deficiency, goats, sheep.

RESUMO.- Para a determinação dos teores de cobre e de seus antagonistas, foram utilizadas 160 amostras de soro e de fígados, de caprinos e ovinos enviados ao matadouro

\footnotetext{
${ }^{1}$ Recebido em 25 de novembro de 2014.

Aceito para publicação em 5 de maio de 2015.

${ }^{2}$ Mestrando em Ciência Animal, Universidade Federal do Vale do São Francisco (Univasf). Endereço particular: Condomínio Villi di Roma, Apto 202, Bl.2, Cajueiro, Juazeiro, BA 48905-370, Brasil. *Autor para correspondência: salvador.veterinario@hotmail.com

${ }^{3}$ Docente de Clínica Médica e Cirúrgica de Grandes Animais, Univasf, Rodovia BR-407 Km 12, Lote 543, Projeto de Irrigação Senador Nilo Coelho s/n, C1, Petrolina, PE 56300-990, Brasil. E-mail: alexandre.antonelli@ univasf.edu.br

${ }^{4}$ Graduando em Medicina Veterinária, Univasf, Rodovia BR-407 Km 12, Lote 543, Proj. Irrigação Senador Nilo Coelho s/n, C1, Petrolina, PE 56300 990. E-mails: dr_marinhorocha@hotmail.com, georgewns@hotmail.com
}

municipal de Petrolina. As amostras de fígado e soro foram correlacionadas para o mesmo animal, a fim de evitar erros na obtenção dos dados. No soro a atividade da ceruloplasmina foi determinada por método colorimétrico. Para a determinação dos minerais, as amostras foram diluídas de seis a vinte vezes com água Milli-Q. Para determinação das concentrações dos elementos minerais no fígado, as amostras foram digeridas até que se obtivesse uma solução que mantivesse os minerais da amostra inicial e que fosse totalmente liquida, sem a presença de partículas sólidas que pudessem obstruir os capilares de sucção do espectrômetro e assim impedir as leituras das amostras. As concentrações de cobre, molibdênio, ferro e zinco foram determinadas através de espectrometria óptica por emissão de plasma (ICP). Desta forma, foi conduzido o experimento objetivan- 
do determinar a ocorrência e distribuição da carência de cobre no território do sertão do vale do rio São Francisco em Pernambuco. Foi observado que não houve carência de cobre nesta região do estado de Pernambuco, quando se avaliou os níveis médios de cobre hepático;. Os níveis de zinco estavam dentro de um padrão de normalidade, enquanto que os níveis de ferro foram mais elevados em ovinos, e os níveis de molibdênio mais reduzidos em caprinos. Verificou-se também que a atividade de ceruloplasmina foi um indicador dos níveis séricos de cobre.

TERMOS INDEXADOS: Ceruloplasmina, cobre, mineral deficiency, caprinos, ovinos.

\section{INTRODUÇÃO}

O Estado de Pernambuco detém um rebanho aproximado de 1.622.511 ovinos e 1.735.051 caprinos (Brasil 2010). Sendo esta uma das atividades mais representativas para os produtores rurais, sobretudo nas regiões do agreste e do sertão do Estado, onde está situado o território do sertão do vale do rio São Francisco. 0 principal rebanho nessa microrregião é o de ovinos com cerca de 329.200 cabeças, seguido do rebanho de caprinos com 292.800 cabeças, representando $22 \%$ e $17,9 \%$ do total do Estado, respectivamente (Brasil 2010). Apesar do grande número de animais existentes nessa região, pouco se sabe sobre a incidência e prevalência das principais doenças que acometem caprinos e ovinos, sobretudo aquelas relacionadas a distúrbios metabólicos e nutricionais. Segundo Tokarnia et al. (2000), em ruminantes, a maioria das deficiências minerais está associada a regiões específicas, relacionadas às características do solo local.

O território do sertão do vale do rio São Francisco localiza-se geograficamente na região Nordeste do Brasil, situado no Semiárido Pernambucano, e é constituído por sete municípios: Afrânio, Cabrobó, Dormentes, Lagoa Grande, Orocó, Petrolina e Santa Maria da Boa Vista.

A atuação e a importância do cobre em sistemas enzimáticos no metabolismo dos ruminantes são bem conhecidas. 0 cobre possui a peculiaridade de se oxidar ou reduzir facilmente, característica fundamental para as metaloenzimas cúpricas que catalisam reações de óxido-redução. Também está presente em algumas metaloproteínas como a ceruloplasmina, que regula a atividade da transferrina, e a metalotioneína, que entre outras funções regula a absorção do próprio cobre pelo organismo (Ortollani 2002). Nos animais, ele participa da formação da mielina e dos ossos, hematopoiese, metabolismo da ligação dos tecidos, pigmentação e formação de lã e pelos. (Cavalheiro \& Trindade 1992, Radostits et al. 2007).

Dentre as espécies domésticas, sem dúvida a ovina é a mais predisposta a desenvolver tanto o quadro carencial como a intoxicação pelo cobre. Estes quadros estão ligados a diferenças marcantes no metabolismo do cobre em determinadas raças de ovinos, pois enquanto algumas têm menores capacidades de retenção do cobre em seus estoques orgânicos, outras o acumulam em quantidade demasiadamente grande (Suttle 2010, Ferreira et al. 2008). Também é reconhecido que ovinos jovens em crescimento são mais susceptíveis a desenvolverem quadros de intoxicação por cobre, pois podem absorver o cobre dietético com eficiência duas a três vezes maior que os adultos (Suttle 2010).

A carência de cobre em ovinos e caprinos pode causar: debilidade e perda da ondulação ou despigmentação da lã ou pelo preto; alterações congênitas ou contraídas da mielina (ataxia enzoótica) em que os cordeiros e cabritos nas primeiras semanas de vida apresentam incoordenação dos membros posteriores, podendo resultar em paraplegia e morte; osteoporose; anemia; baixa imunidade a doenças infecciosas e redução do crescimento (Tokarnia et al. 1966, Maxie 2007, Suttle 2010).

No Brasil, a ataxia enzoótica em ovinos foi descrita pela primeira vez no Estado do Piauí, e mais recentemente em Pernambuco, foi descrito um surto em ovinos e caprinos. Na maioria destes animais, surgia o quadro sintomatológico de incoordenação dos membros pélvicos, quedas frequentes e dificuldade para se manter em estação, diminuição da resposta sensitiva e motora na determinação do reflexo sensitivo na região interdigital dos membros posteriores. Em alguns casos, ocorria paralisia dos anteriores, a qual antecedia o surgimento de espasticidade permanente de todos os membros (Tokarnia et al. 1966, Santos et al. 2006).

Embora a exigência nutricional de caprinos e ovinos esteja relativamente bem estabelecida ainda há pouca informação acerca das necessidades nutricionais de pequenos ruminantes criados nas regiões semiáridas. A maior parte da informação disponível consta de extrapolações calculadas a partir de dados de bovinos (Malafaia et al. 2004). Não obstante, devido a características fisiológicas específicas dos ovinos e caprinos são necessários mais estudos (Aguilera et al. 1990). Ainda, a dosagem de determinados elementos bioquímicos, assim como a atividade de diversas enzimas no sangue pode auxiliar no diagnóstico, no prognóstico e no acompanhamento do tratamento dos animais (Morais et al. 2000).

\section{MATERIAL E MÉTODOS}

Este estudo foi realizado de acordo com os princípios éticos na experimentação animal, sendo que o projeto de pesquisa foi aprovado pelo Comitê de Ética em Estudos Humanos e Animais da Universidade Federal do Vale do São Francisco (CEEHA/Univasf, protocolo 26101071).

As amostras de sangue e fígado foram obtidas de animais encaminhados ao abatedouro municipal de Petrolina, localizado na microrregião de Petrolina, Estado de Pernambuco. Para estabelecer a relação da procedência dos animais com os dados obtidos, foi utilizada a divisão do estado em regiões, conforme estabelecido pela Agência de Defesa e Fiscalização Agropecuária do Estado de Pernambuco.

Foram selecionados de forma aleatória 80 animais de cada espécie, sendo 20 machos e 20 fêmeas durante o período chuvoso e 20 machos e 20 fêmeas durante o período seco, totalizando ao final do experimento 160 animais.

As amostras foram coletadas em dois períodos distintos, seco e chuvoso dos anos de 2011 e 2012, respectivamente, considerando o terço final de cada um destes períodos. A finalidade deste delineamento foi caracterizar amostras obtidas no período onde a disponibilidade de nutrientes aos animais é alta (chuvas) e no pe- 
ríodo onde o animal necessita da mobilização das reservas, pela escassez de alimentos (seca).

Para definir os períodos seco e chuvoso, foram utilizados os registros de dados de temperaturas máximas e mínimas e precipitação pluviométrica junto ao laboratório de meteorologia de Pernambuco (Lamepe-ITEP), definidos pela média histórica para a região. Desta forma, é possível caracterizar que os meses mais chuvosos estão compreendidos entre os meses de novembro e abril do ano subsequente, e o período mais seco ocorre entre os meses de maio e outubro.

De acordo com estes dados e considerando-se apenas o terço final dos referidos períodos, foram definidos os meses de coleta para o período chuvoso (PC) em março e abril, e para o período seco (PS) em setembro e outubro. No abatedouro, os animais foram indicados de forma aleatória pelo responsável pelo abate, respeitando os critérios de inclusão (espécie, sexo e município de procedência do animal).

Amostras de sangue foram colhidas por venopunção jugular, em tubos siliconizados de coleta a vácuo (vacutainer ${ }^{\circledR}$ ) sem anticoagulantes para obtenção de soro. Após centrifugação por 15 minutos a $500 \mathrm{G}$, alíquotas de soro foram acondicionadas em quadruplicata em tubos tipos "Eppendorf" ( $2 \mathrm{ml}$ ) e armazenadas à temperatura de $-20^{\circ} \mathrm{C}$, para análise mineral e atividades enzimáticas.

As amostras de fígado foram obtidas por meio de corte do órgão em cerca de 50 gramas, e fragmentadas com lâmina de bisturi estéril para evitar contaminação, lavados com solução fisiológica estéril, colocados sobre papel filtro para retirada do excesso de sangue e água e alocadas em coletores universais estéreis, devidamente identificados, e armazenados em freezer a $-20^{\circ} \mathrm{C}$.

No soro a atividade da ceruloplasmina foi determinada por método colorimétrico, segundo Schosinsky et al. (1974) e adaptado por López-Alonso et al. (2006).

Para a determinação de minerais, as amostras foram diluídas de seis a vinte vezes com água Milli-Q. Para determinação das concentrações dos elementos minerais no fígado, as amostras foram digeridas até que se obtivesse uma solução que mantivesse os minerais da amostra inicial e que fosse totalmente liquida, sem a presença de partículas sólidas que pudessem obstruir os capilares de sucção do espectrômetro e assim impedir a leitura das amostras, segundo recomendações de Tebaldi et al. (2000).

As concentrações de cobre, molibdênio, ferro e zinco foram determinadas através de espectrometria óptica por emissão de plasma (ICP). A cada análise de 20 amostras era inserido um controle de qualidade interno do laboratório (Miles et al. 2001).

As análises estatísticas foram processadas com auxílio de programa estatístico computadorizado (MINITAB 2000). Os dados obtidos foram primeiramente analisados quanto a sua distribuição normal pela prova de Kolmogorov-Smirnov (Siegel 1975).

Dependendo da distribuição dos dados estes foram avaliados segundo testes estatísticos paramétricos ou não paramétricos. Na ocorrência do primeiro caso, os dados foram inicialmente avaliados por meio de teste $\mathrm{F}$ (análise de variância), e quando significativo, as médias foram confrontadas pelo teste de Duncan (Sampaio 1998). No caso de dados não paramétricos os mesmos foram analisados pelo teste de Mann-Whitney (Siegel 1975). Foram consideradas significativas as diferenças cujo valor de "p" apresentou valores iguais ou inferiores a $0,05(\mathrm{p} \leq 0,05)$.

A análise do Quadro de contingência relativa à frequência de teores de molibdênio foi feita pelo Teste de Qui-Quadrado (Massad et al. 2004). No estudo da relação entre duas variáveis foram calculados os coeficientes de correlação (Snedor \& Cockran 1967). Ficou estabelecido que existiu uma correlação de alta intensidade entre as variáveis quando $r \geq 0,60$; média intensidade quando $0,30<r<0,60$; e de baixa intensidade quando $r \leq 0,30$, considerando também que o nível de significância obtido nas correlações seja igual ou inferior a 5\% (Little \& Hills 1978).

\section{RESULTADOS E DISCUSSÃO}

Apenas animais dos municípios de Petrolina, Dormentes e Santa Maria da Boa Vista foram abatidos, portanto a representatividade dessa região contempla apenas estes municípios. No Quadro 1 verificou-se a distribuição dos animais por origem, onde foi possível observar que durante o período seco a maioria dos animais abatidos no abatedouro municipal foi proveniente do próprio município de Petrolina, já que a amostragem foi proporcional aos lotes que chegavam ao abatedouro.

Os valores de cobre sérico não tiveram variação significativa quando comparados com os resultados obtidos no período seco com os obtidos no período chuvoso em todas as categorias estudadas; entretanto, apenas ao compararmos os resultados obtidos pelos caprinos no período seco, verificou-se que os machos apresentaram valores significativamente superiores aos encontrados nas fêmeas, como mostra o Quadro 2.

Quadro 1. Distribuição dos caprinos e ovinos participantes da amostragem conforme o município de origem

\begin{tabular}{|c|c|c|c|c|c|c|}
\hline \multirow[b]{2}{*}{ Municípios } & \multicolumn{3}{|c|}{ Período seco } & \multicolumn{3}{|c|}{ Período chuvoso } \\
\hline & Macho & Fêmea & Total & Macho & Fêmea & Total \\
\hline Dormentes & $40 / 5 c$ & $50 / 3 c$ & $90 / 8 c$ & $8 o / 8 c$ & $8 o / 8 c$ & $16 o / 16 c$ \\
\hline Petrolina & $13 \mathrm{o} / 10 \mathrm{c}$ & $12 o / 12 c$ & $25 o / 22 c$ & $80 / 8 c$ & $80 / 8 c$ & $16 o / 16 c$ \\
\hline $\begin{array}{l}\text { Santa Maria } \\
\text { da Boa Vista }\end{array}$ & $3 o / 5 c$ & $3 o / 5 c$ & $60 / 10 c$ & $4 o / 4 c$ & $4 o / 4 c$ & $8 o / 8 c$ \\
\hline
\end{tabular}

Vista

Total 40

$\overline{\mathrm{o}=\text { ovinos }, \mathrm{c}=\text { caprinos }}$

Quadro 2. Valores médios e desvios padrão dos teores séricos de cobre, zinco, ferro e molibdênio $(\mu \mathrm{mol} / \mathrm{L})$ em pequenos ruminantes do território do sertão do vale do rio São Francisco

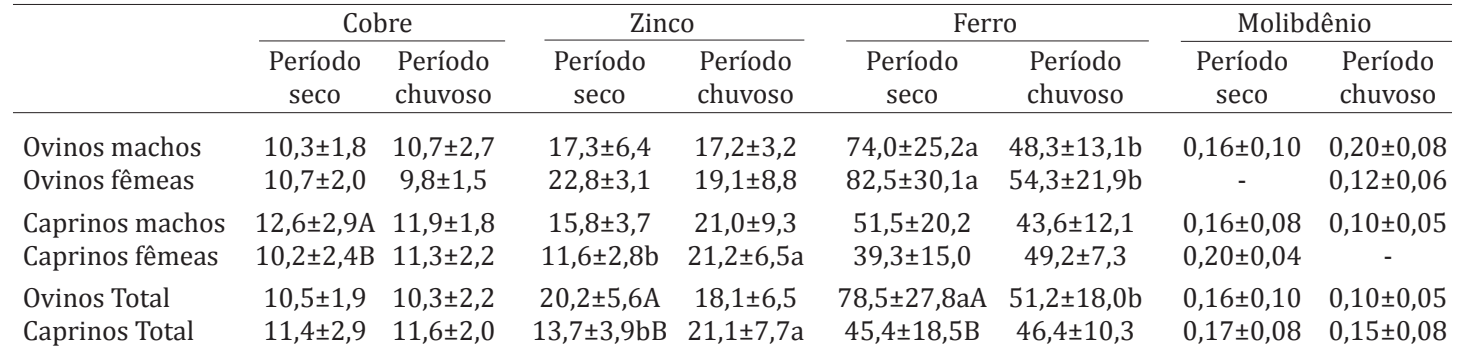

Letras minúsculas distintas nas linhas indicam diferenças significativas entre os períodos para cada mineral ( $\mathrm{p}<0,05)$. Letras maiúsculas distintas nas colunas indicam diferenças significativas entre os grupos $(\mathrm{p}<0,05)$. 
Verificou-se que os teores de cobre sérico em ovinos mostrados no Quadro 2 variaram de 9,8 a 10,7 $\mu \mathrm{mol} / \mathrm{L}$, sem que houvesse diferença significativa entre machos e fêmeas ou entre os períodos seco e chuvoso, e estes resultados estão dentro dos valores apresentados por Kaneko et al. (1997) $(9,13-25,2 \mu \mathrm{mol} / \mathrm{L})$, e próximos aos resultados relatados por Marques et al. (2011), sendo que este, mostra resultados obtidos na microrregião de Araripina, também localizada no sertão do Estado de Pernambuco. Sousa et al. (2012), em um estudo realizado em Mossoró-RN, encontraram valores médios de cobre plasmático de 5,9 e 5,2 $\mu \mathrm{mol} / \mathrm{L}$ em duas propriedades deste município, onde ocorreu surto de ataxia enzoótica.

As médias de cobre sérico nos caprinos variaram de 10,2 a $12,6 \mu \mathrm{mol} / \mathrm{L}$, e foram compatíveis com o que mostra a literatura, onde Marques (2010) relata valores de $11,37 \pm 2,57$. Já Van Niekerk et al. (1990) mostraram valores de 12,6-25,2 $\mu \mathrm{mol} / \mathrm{L}$ e Solaiman et al. (2007) apresentaram valores médios de $18,11 \pm 0,63 \mu \mathrm{mol} / \mathrm{L}$. Como os teores de cobre sérico e hepáticos estiveram dentro dos parâmetros de normalidade segundo vários autores, explica-se a baixa relação entre estes dois parâmetros $(\mathrm{r}=0,06)$. Caso houvesse uma carência pronunciada, ou uma iminente intoxicação, teríamos uma relação mais elevada, conforme mostrou Antonelli (2007).

Os valores séricos de zinco não tiveram variação significativa entre os grupos de ovinos, tanto entre os períodos, como entre os sexos nos períodos. Quando comparados os resultados dos caprinos entre os períodos, os machos não apresentaram diferença significativa, verificou-se que as fêmeas apresentaram valores significativamente mais altos no período chuvoso do que no período seco. Assim como quando comparados os valores médios de todos caprinos, o período chuvoso foi o que teve valores significativamente maiores do que o período seco. Quando se comparou os valores obtidos por ovinos e caprinos, foi possível verificar que os ovinos tiveram valores médios significativamente superiores aos obtidos pelos caprinos no período seco, entretanto no período chuvoso não houve diferença significativa entre as espécies, como demonstrado no Quadro 2.

Ao analisarmos os resultados referentes aos teores séricos de ferro, é possível verificar que os ovinos apresentaram valores médios significativamente superiores no período seco em relação ao período chuvoso, tanto para machos, fêmeas, como para os ovinos em geral. Não houve diferença significativa entre machos e fêmeas de ovinos em nenhum período. Quando se avaliaram os resultados dos caprinos, não houve diferença significativa entre os períodos seco e chuvoso tanto para os machos, fêmeas como para os caprinos em geral. Foi possível verificar que os ovinos tiveram valores médios significativamente superiores de ferro sérico quando comparados aos obtidos nos caprinos no período seco, enquanto que no período chuvoso não houve diferença significativa entre as espécies (Quadro 2).

Em uma parcela significativa das amostras os teores de molibdênio sérico encontravam-se abaixo do limiar de calibração e determinação do aparelho de espectrometria óptica por emissão de plasma, e desta forma a análise estatística referente a esta variável foi realizada de forma
Quadro 3. Frequência dos animais com teores séricos de molibdênio acima e abaixo de $0,05 \mu \mathrm{mol} / \mathrm{L}$ em pequenos ruminantes do território do sertão do vale do Rio São Francisco

\begin{tabular}{|c|c|c|c|c|c|}
\hline & \multicolumn{2}{|c|}{ Período seco } & \multicolumn{2}{|c|}{ Período chuvoso } & \multirow[t]{2}{*}{ Valor de $\mathrm{p}$} \\
\hline & $>0,05$ & $<0,05$ & $>0,05$ & $<0,05$ & \\
\hline Ovinos machos & 13 & 7 & 6 & 14 & 0,0267 \\
\hline Ovinos fêmeas & 0 & 20 & 8 & 12 & 0,0016 \\
\hline Valor de p & $<0,0001$ & 0,5073 & & & \\
\hline Caprinos machos & 9 & 11 & 7 & 13 & 0,5186 \\
\hline Caprinos fêmeas & 3 & 17 & 0 & 20 & 0,0717 \\
\hline Valor de $\mathrm{p}$ & \multicolumn{2}{|c|}{0,0384} & \multicolumn{2}{|c|}{0,0036} & \\
\hline Ovinos Total & 13 & 27 & 14 & 26 & 0,8131 \\
\hline Caprinos Total & 12 & 28 & 7 & 33 & 0,1890 \\
\hline Valor de $\mathrm{p}$ & \multicolumn{2}{|c|}{0,8094} & \multicolumn{2}{|c|}{0,0753} & \\
\hline
\end{tabular}

Valor de p na linha para a diferença entre os períodos. Valor de p na coluna das $1^{\underline{a}}$ e $2^{\underline{a}}$ seções para a diferença entre sexo, e na $3^{\underline{a}}$ seção para a diferença entre espécies.

diferenciada, através do teste de Qui-Quadrado com a finalidade de compararmos as proporções de cada categoria variando em sexo, período e teor de molibdênio maior ou menor do que $0,05 \mu \mathrm{mol} / \mathrm{L}$, conforme mostrado no Quadro 3. Desta forma, verificou-se a ocorrência de uma diminuição na frequência de ovinos machos com teor de molibdênio acima de $0,05 \mu \mathrm{mol} / \mathrm{L}$ no período chuvoso em relação ao período seco, enquanto que com as fêmeas ocorreu o inverso. Quando verificado a influência do sexo, observou-se que apenas no período seco ocorreu diferença significativa, onde os machos apresentaram um número maior de animais com teor de molibdênio acima de 0,05 $\mu \mathrm{mol} / \mathrm{L}$, enquanto que nas fêmeas prevaleceu animais com teor abaixo deste valor. Em relação aos caprinos, verificou-se que não houve influência do período na quantidade de animais em relação ao teor de molibdênio sérico, mas foi verificado que em ambos os períodos a quantidade de caprinos machos com teor de molibdênio acima de $0,05 \mu \mathrm{mol} / \mathrm{L}$ foi superior ao de fêmeas de caprinos. Não houve diferença significativa de frequência entre as espécies, tampouco entre os períodos quando o fator sexo não foi considerado.

Conseguiu-se analisar comparativamente as médias das amostras em que os teores de molibdênio apresentavam-se acima de 0,05 $\mu \mathrm{mol} / \mathrm{L}$ (exceto para fêmeas de ovinos no período seco e fêmeas de caprinos no período chuvoso), e não houve diferença significativa entre ovinos machos e fêmeas em nenhum dos períodos, assim como não houve diferença entre os períodos. Quando se avaliou os resultados obtidos pelos caprinos, não ocorreu diferença significativa em nenhum momento. Também não ocorreram diferenças entre as espécies em nenhum dos períodos, conforme demonstrado no Quadro 2.

Os valores de cobre hepático não apresentaram variação significativa quando comparados os resultados obtidos no período seco com os obtidos no período chuvoso, em todas as categorias estudadas, assim como não ocorreram diferenças entre as espécies em nenhum dos períodos, conforme demonstrado no Quadro 4 e na Figura 1.

Quando se avaliaram os valores hepáticos de zinco em ovinos, verificou-se uma variação significativa apenas entre os machos do período seco comparados aos do período chuvoso, onde estes últimos apresentaram valores médios 
Quadro 4. Valores médios e desvios padrão dos teores hepáticos de cobre, zinco, ferro e molibdênio (ppm) em pequenos ruminantes do território do sertão do vale do rio São Francisco

\begin{tabular}{|c|c|c|c|c|c|c|c|c|}
\hline & \multicolumn{2}{|c|}{ Cobre } & \multicolumn{2}{|c|}{ Zinco } & \multicolumn{2}{|c|}{ Ferro } & \multicolumn{2}{|c|}{ Molibdênio } \\
\hline & $\begin{array}{c}\text { Período } \\
\text { seco }\end{array}$ & $\begin{array}{l}\text { Período } \\
\text { chuvoso }\end{array}$ & $\begin{array}{c}\text { Período } \\
\text { seco }\end{array}$ & $\begin{array}{l}\text { Período } \\
\text { chuvoso }\end{array}$ & $\begin{array}{l}\text { Período } \\
\text { seco }\end{array}$ & $\begin{array}{l}\text { Período } \\
\text { chuvoso }\end{array}$ & $\begin{array}{c}\text { Período } \\
\text { seco }\end{array}$ & $\begin{array}{l}\text { Período } \\
\text { chuvoso }\end{array}$ \\
\hline Ovinos machos & $217 \pm 133$ & $236 \pm 110$ & $104 \pm 21 b$ & $133 \pm 50 a$ & $267 \pm 113$ & $225 \pm 101$ & $3,0 \pm 1,1$ & $3,1 \pm 0,6$ \\
\hline Ovinos fêmeas & $245 \pm 173$ & $295 \pm 206$ & $111 \pm 19$ & $110 \pm 20$ & $233 \pm 103$ & $255 \pm 116$ & $3,3 \pm 1,3 a$ & $2,4 \pm 0,8 b$ \\
\hline Caprinos machos & $210 \pm 133$ & $295 \pm 163$ & $118 \pm 21$ & $111 \pm 163$ & $136 \pm 53$ & $145 \pm 64$ & $2,7 \pm 1,1 \mathrm{a}$ & $0,8 \pm 0,5 b$ \\
\hline Caprinos fêmeas & $211 \pm 114$ & $266 \pm 147$ & $107 \pm 22$ & $109 \pm 18$ & $162 \pm 42$ & $155 \pm 68$ & $2,4 \pm 0,9 a$ & $0,9 \pm 0,8 b$ \\
\hline Ovinos Tota & $230 \pm 151$ & $266 \pm 166$ & $107 \pm 20$ & $122 \pm 39$ & $250 \pm 108 \mathrm{~A}$ & $240 \pm 108 \mathrm{~A}$ & $3,2 \pm 1,2 \mathrm{~A}$ & $2,7 \pm 0,8 \mathrm{~A}$ \\
\hline Caprinos Total & $211 \pm 120$ & $280 \pm 154$ & $113 \pm 22$ & $110 \pm 21$ & $149 \pm 49 B$ & $150 \pm 66 B$ & $2,5 \pm 1,0 \mathrm{aB}$ & $0,8 \pm 0,7 \mathrm{bB}$ \\
\hline
\end{tabular}

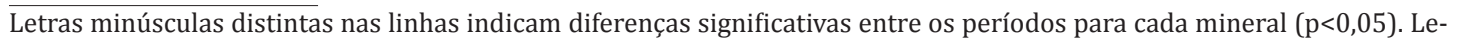
tras maiúsculas distintas nas colunas indicam diferenças significativas entre os grupos $(\mathrm{p}<0,05)$.

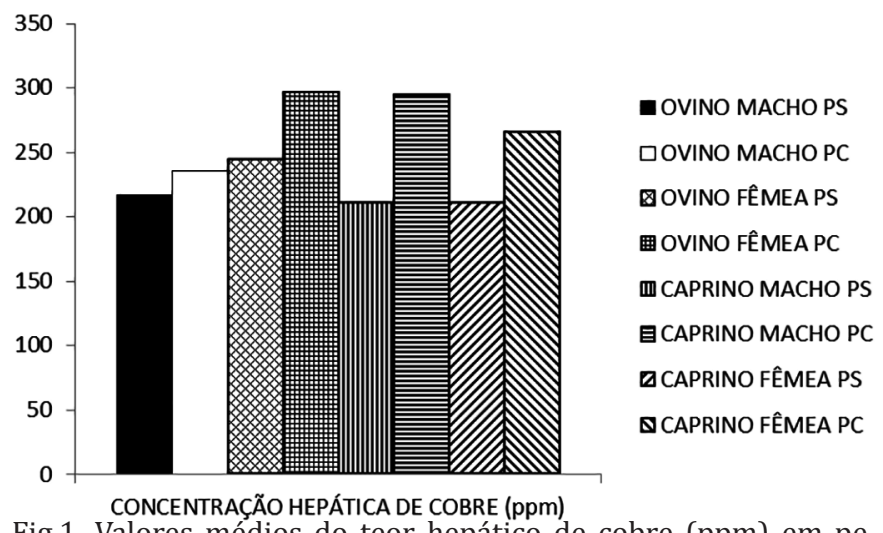

Fig.1. Valores médios do teor hepático de cobre (ppm) em pequenos ruminantes do território do sertão do vale do rio São Francisco, separados por sexo e período.

mais altos. Entretanto nas fêmeas, ou comparados machos e fêmeas não houve diferença significativa. Quando comparados os resultados dos caprinos entre os períodos ou entre sexos em cada período não houve diferença significativa, assim como não ocorreram diferenças entre as espécies em nenhum dos períodos, conforme demonstrado no Quadro 4.

Van Niekerk et al. (1990) mostraram valores para zinco abaixo de $12,2 \mu \mathrm{mol} / \mathrm{L}$ tanto para ovinos como caprinos, que segundo os autores indicava uma deficiência marginal deste elemento. Neste estudo, apenas as fêmeas de caprinos no período seco mostraram valores médios inferiores ao descrito por Van Niekerk et al. (1990), sugerindo uma deficiência marginal deste elemento neste período. Suttle (2010) afirmou que o valor limite inferior de normalidade para zinco sérico em ovinos e caprinos é de $10 \mu \mathrm{mol} / \mathrm{L}$. Em ambos os casos as fêmeas de caprinos citadas estariam dentro dos valores de normalidade, mas muito próximas de valores de deficiência.

Os teores de zinco hepático encontrados neste trabalho (104-133ppm) estiveram condizentes com o relatado por Tokarnia et al. (1988), que afirmaram que os teores de zinco hepáticos variavam na normalidade entre 101 e $200 \mathrm{ppm}$, e um pouco abaixo para algumas categorias e períodos do encontrado por Marques (2010), cujos valores médios foram de 128,7ppm, assim como por Antonelli (2007) em ovinos, que relatou valores normais de $120-138 \mathrm{ppm}$. 0 zinco é o principal estimulador da síntese de metalotioneína hepática. Segundo López-Alonso et al. (2005) quanto maior a concentração de zinco no fígado maior é o teor de metalotioneína neste órgão $\left(R^{2}=0,69\right)$. Esse composto é responsável pela complexação com o cobre estocado no órgão para ser posteriormente excretado pela bile no processo de desintoxicação.

Os resultados obtidos neste trabalho, tanto para zinco sérico como para zinco hepático podem ser considerados dentro da normalidade segundo alguns autores, entretanto, próximos do limite inferior de normalidade. Como a absorção de zinco é influenciada pela presença de antagonistas como cobre, cálcio e ferro, e neste trabalho apurou-se valores relativamente elevados de ferro, o que pode ter contribuído para a diminuição da absorção do zinco. Desta forma, sugere-se avaliar no futuro a possível ocorrência de problemas de infertilidade e baixo ganho de peso nestas regiões onde foram comprovados baixos teores de zinco.

Quando se avaliou os teores de ferro hepático, tanto ovinos quanto caprinos não apresentaram variação significativa de quando comparados os valores médios obtidos no período seco com os obtidos no período chuvoso, em todas as categorias estudadas. A comparação quando feita entre as espécies, os ovinos apresentaram valores médios de ferro hepático significativamente superiores aos caprinos tanto no período seco quanto no período chuvoso, demostrados no Quadro 4 e Figura 2.

Dados interessantes foram obtidos a partir do ferro sérico, pois os ovinos apresentaram valores significativamen-

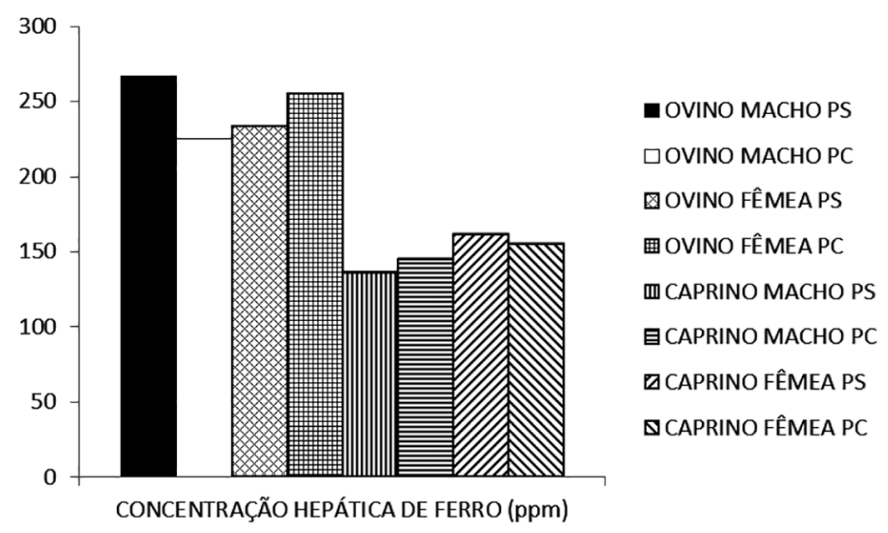

Fig.2. Valores médios do teor hepático de ferro (ppm) em pequenos ruminantes do território do sertão do vale do rio São Francisco, separados por sexo e período. 
te superiores no período seco $(78,5 \mu \mathrm{mol} / \mathrm{L})$ em relação ao período chuvoso $(51,2 \mu \mathrm{mol} / \mathrm{L})$, assim como em relação aos caprinos (45,4 $\mu \mathrm{mol} / \mathrm{L})$. Segundo Kaneko et al. (1997), a concentração sérica de ovinos é de 29,7-39,7 $\mu \mathrm{mol} / \mathrm{L}$, enquanto que Suttle (2010) considerou normal o valor médio de $34,6 \pm 1,25 \mu \mathrm{mol} / \mathrm{L}$ para ovinos e de $17-36 \mu \mathrm{mol} / \mathrm{L}$ para caprinos, e Blood (1994) considerava como normal, valores médios de $37,4 \mu \mathrm{mol} / \mathrm{L}$. Analisando os dados obtidos neste estudo, todos os animais apresentaram valores séricos acima do considerando dentro de parâmetros de normalidade dos autores acima citados. Contudo, houve controvérsias na literatura, pois Suttle (2010) afirmou que ovinos podem apresentar valores de ferro sérico que são de $18,2-54,4 \mu \mathrm{mol} / \mathrm{L}$, e desta forma apenas os ovinos do período seco apresentaram valores superiores aos considerados dentro da normalidade. Marques (2010) obteve valores que foram de 25,06-35,58 $\mu \mathrm{mol} / \mathrm{L}$ para ferro sérico em uma região próxima à deste estudo, fato que pode ser explicado pela condição de pluviosidade mais favorável nos municípios alvo de seu estudo (Granito, Ouricuri e Araripina). Segundo os autores supracitados, o limite para o animal iniciar o desenvolvimento de carência é de $29 \mu \mathrm{mol} / \mathrm{L}$ de ferro sérico, sendo considerado fator de risco para situação de deficiência, enquanto que valores superiores a $39 \mu \mathrm{mol} / \mathrm{L}$ são indicativos de excesso de ferro sérico.

Os resultados de ferro hepático obtidos neste estudo mostraram valores mais elevados em ovinos do que em caprinos, sendo superiores aos valores achados por Marques (2010) (156,1-210,5ppm). Tokarnia et al. (1988) encontraram valores de 181-380ppm de ferro hepático. Estas concentrações mais elevadas no soro e fígado de ovinos podem estar associadas ao hábito alimentar desta espécie, que, segundo Leite (2002), são classificados como utilizadores de volumosos, preferindo mais dicotiledôneas herbáceas e gramíneas, ou seja, pastejam mais próximos ao solo. Ao passo que caprinos são classificados como selecionadores intermediários, adaptados a incluir em sua dieta grande variedade de plantas, com um comportamento oportunista e adaptativo ao que o meio ambiente oferece de acordo com a disponibilidade de forragem e a estação do ano, preferindo dicotiledôneas herbáceas e brotos e folhas de arvores e de arbustos (Araújo Filho et al. 1996, Leite 2002). Associado a teores de ferro disponíveis nos solos de referência de Pernambuco considerados de médio a alto (Oliveira \& Nascimento 2006), podemos sugerir que o hábito de ingerir vegetação mais rasteira predispõe a ingestão de solo com ferro, aumentando os teores deste elemento no organismo. Santos et al (2006) aventaram esta possibilidade, ao considerarem que no período de seca as pastagens tornam-se mais escassas forçando os animais a pastarem mais rente ao solo, sendo este rico em ferro (8600ppm), além de terem verificado que por ser um solo arenoso recobria, em forma de poeira, as forragens disponíveis para os animais, forçando os animais a ingerirem altas quantidade de ferro.

Apesar de Santos et al. (2006) e Suttle (2010) inferirem a deficiência de cobre ao excesso de ferro, neste trabalho os teores médios de cobre não se encontram em quantidades deficientes, havendo uma baixa relação entre o ferro e o cobre hepático.
Ao serem avaliados os teores hepáticos de molibdênio em ovinos, foi possível verificar que as fêmeas apresentaram valores médios significativamente superiores no período seco em relação ao período chuvoso, fato que não ocorreu com os machos. Quando comparados os sexos dentro de cada período, não houve diferença significativa entre sexo e período para os ovinos. Quando foram analisados os resultados dos caprinos, tanto os machos quanto as fêmeas apresentaram valores médios significativamente superiores no período seco em relação ao período chuvoso, sem que houvesse diferença significativa entre os sexos em ambos os períodos. Ao comparar os caprinos em geral, o período seco apresentou valores médios significativamente superiores aos do período chuvoso. E na comparação dos valores médios de molibdênio hepático obtidos para ovinos e caprinos, foi possível verificar que os ovinos mostraram valores médios significativamente superiores aos obtidos pelos caprinos tanto no período seco como no período chuvoso, conforme mostra a o Quadro 4 e Figura 3.

A concentração sérica de molibdênio mostrou resultados surpreendentes, considerando os valores extremamente baixos, considerando a literatura existente. Verificou-se que $71,25 \%$ dos animais apresentaram valores de molibdênio sérico inferiores a $0,05 \mu \mathrm{mol} / \mathrm{L}$. Não foi possível determinar o teor exato de molibdênio nestas amostras, pois a curva de calibração do aparelho de espectrometria óptica por emissão de plasma não permitia determinação de valores inferiores. Mesmo quando avaliaram-se os valores séricos dos materiais que possibilitaram leitura pelo aparelho, estes foram extremamente baixos variando de 0,10 a $0,20 \mu \mathrm{mol} / \mathrm{L}$, resultados compatíveis apenas com Pott et al. (1999) cujo valor médio de molibdênio sérico foi de $0,10 \mu \mathrm{mol} / \mathrm{L}$, ligeiramente superiores aos encontrados por Antonelli (2007), que encontrou valor sérico médio de 0,8 $\mu \mathrm{mol} / \mathrm{L}$.

Quanto aos teores hepáticos de molibdênio, verificou-se que, exceto para os caprinos no período chuvoso $(0,8 \mathrm{ppm})$, os valores médios obtidos variaram entre 2,4 e 3,3ppm, que estão compatíveis com os resultados mostrados por diversos autores, apesar da grande variação dos resultados apresentados. Desta forma, sugere-se que estudos posteriores com este microelemento em animais sejam conduzidos

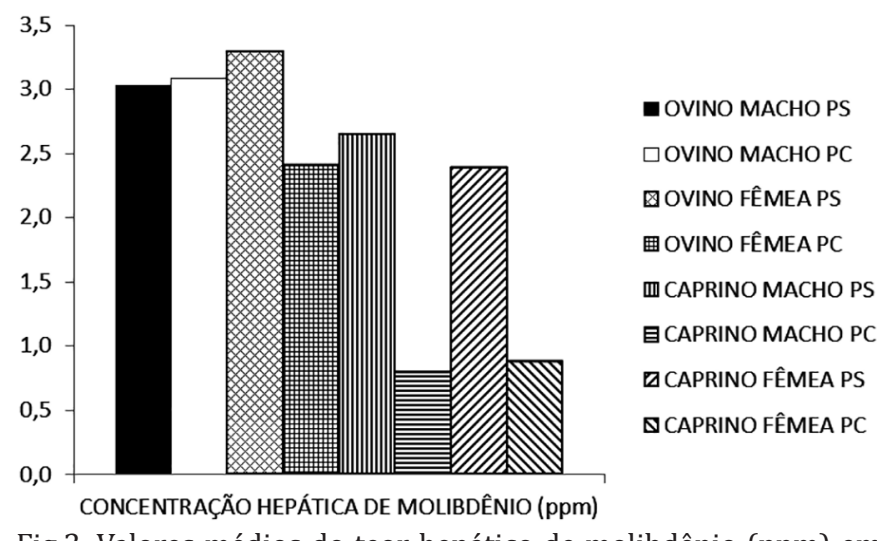

Fig.3. Valores médios do teor hepático de molibdênio (ppm) em pequenos ruminantes do território do sertão do vale do rio São Francisco, separados por sexo e período. 
Quadro 5. Valores médios e desvios padrão da atividade sérica da ceruloplasmina (UI/L) em pequenos ruminantes do território do sertão do vale do rio São Francisco

\begin{tabular}{lcc}
\hline & Período seco & Período chuvoso \\
\hline Ovinos Machos & $7,9 \pm 4,8 \mathrm{~b}$ & $22,2 \pm 15,8 \mathrm{a}$ \\
Ovinos Fêmeas & $11,1 \pm 5,8 \mathrm{~b}$ & $19,6 \pm 6,8 \mathrm{a}$ \\
Caprinos Machos & $10,3 \pm 6,5 \mathrm{~b}$ & $28,7 \pm 9,3 \mathrm{a}$ \\
Caprinos Fêmeas & $5,8 \pm 4,4 \mathrm{~b}$ & $28,9 \pm 11,6 \mathrm{a}$ \\
Ovinos Total & $9,5 \pm 5,5 \mathrm{~b}$ & $20,9 \pm 12,0 \mathrm{a} \mathrm{B}$ \\
Caprinos Total & $8,1 \pm 5,9 \mathrm{~b}$ & $28,8 \pm 10,4 \mathrm{aA}$
\end{tabular}

Letras minúsculas distintas nas linhas indicam diferenças significativas entre os períodos $(\mathrm{p}<0,05)$. Letras maiúsculas distintas nas colunas indicam diferenças significativas entre os grupos $(\mathrm{p}<0,05)$.

concomitantemente com a determinação de seus teores no solo e alimentos para uma maior compreensão de seu status no organismo, apesar de que sua principal atuação seja de antagonismo em relação ao metabolismo de cobre. Os valores muito baixos de molibdênio encontrados neste trabalho podem explicar os teores não muito baixos de cobre, o que seria esperado em animais criados extensivamente na região de sertão.

Analisaram-se os resultados referentes à atividade sérica da ceruloplasmina, e foi possível verificar que tanto os ovinos como os caprinos, machos e fêmeas, apresentaram valores médios significativamente superiores no período chuvoso em relação ao período seco. Entretanto, não houve diferença significativa entre machos e fêmeas de ambas as espécies tanto no período chuvoso quanto no período seco, conforme mostra o Quadro 5.

Quando comparados os valores médios obtidos entre as espécies, foi determinado que os caprinos apresentaram valores superiores aos ovinos em geral durante o período chuvoso, sendo que durante o período seco não houve diferença significativa como pôde ser observado no Quadro 5.

A atividade da ceruloplasmina analisada neste trabalho mostrou alta relação para caprinos e ovinos em ambos os períodos. As dosagens de ceruloplasmina podem ser realizadas de acordo com sua concentração sérica ou sua atividade oxidativa sérica. A atividade oxidativa sérica da ceruloplasmina está relacionada com a concentração sérica de cobre, isto é, baixa concentração desse elemento está associada à menor atividade de ceruloplasmina $(\mathrm{r}=0,67)$.

\section{CONCLUSÕES}

Baseado nos teores médios obtidos para o cobre sérico e hepático, os caprinos e ovinos criados no território do sertão do vale do rio São Francisco não apresentam carência de cobre primária ou secundária;

Os ovinos possuíram teores de ferro sérico muito elevados, sugerindo maior ingestão deste elemento devido ao hábito alimentar da espécie;

A atividade de ceruloplasmina é um bom indicador do status de cobre sérico marginal em pequenos ruminantes.

\section{REFERÊNCIAS}

Aguilera J.F., Prieto C. \& Fonollá J. 1990. Protein and energy metabolism of lactating Granadina goats. Brit. J. Nutr. 63:165-175.

Antonelli A.C. 2007. Avaliação do uso de um sal mineral rico em molibdê- nio na prevenção da intoxicação cúprica acumulativa em ovinos. Tese de Doutorado, Faculdade de Medicina Veterinária e Zootecnia, Universidade de São Paulo, São Paulo, SP. 122p.

Araújo Filho J.A., Sousa F.B. \& Carvalho F.C. 1996. Composição botânica e química da dieta de ovinos e caprinos em pastoreio combinado na região dos Inhamuns, Ceará. Revta Soc. Bras. Zootec. 25:383-395.

Blood D.C. 1994. Manual de Medicina Veterinária. Interamericana McGrawHill, Philadelphia. 790p.

Botha C.J., Geswan G.E. \& Minnaar P.P. 1995. Pharmacokinetics of ammonium tetrathiomolybdate following intravenous administration in sheep. J. S. Afr. Vet. Assoc. 66(1): 6-10.

Brasil 2010. Produção da Pecuária Municipal. Instituto Brasileiro de Geografia e Estatística (IBGE), Ministério do Planejamento, Orçamento e Gestão, Brasília, DF. 65p.

Brasil 2011. Relatório de Gestão do Exercício de 2010. Ministério do Desenvolvimento Agrário. Secretária de Desenvolvimento Territorial, Brasília, DF. 516p.

Cavalheiro A.C.L. \& Trindade D.S. 1992. Os Minerais para Bovinos e Ovinos Criados em Pastejo. Sagra-DC Luzzatto, Porto Alegre, RS. 142p.

Embrapa 2013. Precipitação pluviométrica mensal (mm) da Estação Agrometeorológica de Bebedouro, Petrolina/PE (09 $\left.09^{\prime} \mathrm{S} 40^{\circ} 22^{\prime} \mathrm{W}\right)$, Período 1975-2013. Disponível em <http://www.cpatsa.embrapa.br:8080/servicos/dadosmet/ceb-chuva.html> Acesso em 15 mai. 2013.

Ferreira M.B., Antonelli A.C. \& Ortolani E.L. 2008. Intoxicação por cobre, selênio, zinco e cloreto de sódio, p.665-697. In: Spinmosa H.S., Górniak S.L. \& Palermo-Neto J. (Eds), Toxicologia Aplicada à Medicina Veterinária. Manole, Barueri.

Kaneko J.J., Harvey J.W. \& Bruss M.L. 1997. Clinical Biochemistry of Domestic Animals. 5th ed. Academic Press, San Diego. 932p.

Leite E.R. 2002. Manejo alimentar de caprinos e ovinos em pastejo no nordeste do Brasil. Ciênc. Anim. Bras. 2(2):119-128.

Little T.M. \& Hills F.J. 1978. Agricultural Experimentation: design and analysis. John Wiley, New York. 350p.

López-Alonso M., Prieto F., Miranda M., Castillo C., Hernandéz J. \& Benedito J.L. 2005. The role of metallothionein and zinc in hepatic copper accumulation in cattle. Vet. J. 169:262-267.

López-Alonso M., Crespo A., Miranda M., Castillo C., Hernández J. \& Benedito J.L. 2006. Assessment of some blood parameters as potential markers of hepatic copper accumulation in cattle. J. Vet. Diagn. Invest. 18(1):71-75.

Malafaia P., Pimentel V.A., Freitas K.P., Coelho C.D., Brito M.F. \& Peixoto P.V. 2004. Desempenho ponderal, aspectos econômicos, nutricionais e clínicos de caprinos submetidos a dois esquemas de suplementação mineral. Pesq. Vet. Bras. 21(1):15-22.

Maranhão R.L.A. 2013. Dinâmica da produção de ovinos no Brasil durante o período de 1976 a 2010. Dissertação de Mestrado, Instituto de Ciências Humanas, Universidade de Brasília, Brasília, DF. 42p.

Marques A.V.S. 2010. Teores de cobre e seus principais antagonistas em fígado e sangue de ovinos e caprinos criados no estado de Pernambuco. Dissertação de Mestrado, Departamento de Medicina Veterinária, Universidade Federal Rural de Pernambuco, Recife, PE. 66p.

Marques A.V.S., Soares P.C., Riet-Correa F., Mota I.O., Silva T.L.A., Borba Neto A.V., Soares F.A.P. \& Alencar S.P. 2011. Teores séricos e hepáticos de cobre, ferro, molibdênio e zinco em ovinos e caprinos no estado de Pernambuco. Pesq. Vet. Bras. 31(5):398-406.

Massad E., Menezes R.X., Silveira P.S.P. \& Ortega N.R.S. 2004. Métodos Quantitativos em Medicina. Manole, Barueri. 561p.

Maxie M.G. 2007. Jubb, Kennedy and Palmer's Pathology of Domestic Animals. 5th ed. Elsevier, St. Louis. 2340p.

Miles P.H., Wilkinson N.S. \& McDowell L.R. 2001. Analysis of Minerals for Animal Nutrition Research. 3rd ed. University Press, Florida. 117p.

MINITAB 2000. The student edition of MINITAB statistical software adapted for education: 13.0 release: user's manual. Wesley, New York. $624 \mathrm{p}$.

Morais M.G., Rangel J.M., Madureira J.S. \& Silveira A.C. 2000. Variação sa- 
zonal da bioquímica clínica de vacas aneloradas sob pastejo contínuo de Brachiaria decumbens. Arq. Bras. Med. Vet. Zootec. 52(2):98-104.

NRC 2007. Nutrient Requirements of Small Ruminants: sheep, goats, cervids, and New World camelids. Committee on the Nutrient Requirements of Small Ruminants. National Research Council, Washington, DC. National Academy Press, Wasington, DC. 384p.

Oliveira A.B. \& Nascimento W.A. 2006. Formas de manganês e ferro em solos de referência de Pernambuco. Revta Bras. Ciênc. Solo 30(1):99-110.

Ortolani E.L. 2002. Macro e microelementos, p.641-651. In: Spinosa H.S., Górniak S.L. \& Bernardi M.M. (Eds), Farmacologia Aplicada à Medicina Veterinária. $3^{\underline{a}}$ ed. Guanabara Koogan, Rio de Janeiro.

Pott E.B., Henry P.R., Zanetti M.A., Rao P.V., Hinderberger E.J. \& Ammerman C.B. 1999. Effetcs of hight molybdenum concentration and duration of feeding time on molybdenum and copper metabolism in sheep. Anim. Feed Sci. Technol. 79:93-105.

Radostits O.M., Gay C.C., Hinchcliff K.W. \& Constable P.D. 2007. Veterinary Medicine: a textbook of the diseases of cattle, horses, sheep, pigs, and goats. 10th ed. Saunders Elsevier, Philadelphia. 2156p.

Riet-Correa F., Schild A.L., Méndez M.C. \& Lemos R.A.A. 2006. Doenças de Ruminantes e Equinos. Vol.2. 2ª ed. Varela, São Paulo. 574p.

Sampaio I.B.M. 1998. Estatística Aplicada à Experimentação Animal. Fundação de Ensino e Pesquisa em Medicina Veterinária e Zootecnia, Belo Horizonte, MG. 221p.

Santos N.V.M., Sarkis J.E.S., Guerra J.L., Maiorka P.C., Hortelani M.A., Silva F.F. \& Ortolani E.L. 2006. Avaliação epidemiológica, clínica, anatomopatológica e etiológica de surtos de ataxia em cabritos e cordeiros. Ciência Rural 36(4):1207-1213.

Schosinsky K.H., Lehmann H.P. \& Beeler M.F. 1974. Measurement of ceruloplasmin from its oxidase activity in serum by use of dianisidine dihydrochloride. Clin. Chem. 20(12):1556-1563.
Siegel S. 1975. Estatística Não Paramétrica. McGraw-Hill, São Paulo. 350p. Snedcor G.W. \& Cochran W.G. 1967. Statistical Methods. 6th ed. Iowa State University Press, Ames. 593p.

Solaiman T.J., Craig J.R., Reddy G. \& Shoemaker C.E. 2007. Effect of high levels of $\mathrm{Cu}$ supplement on growth performance, rumen fermentation, and immune responses in goat kids. Small Rumin. Res. 69(1):115-123.

Sousa I.K.F., Minervino A.H.H., Sousa R.S., Chaves D.F., Soares H.S., Barros I.O., Araújo C.A.S.C., Barrêto Júnior R.A. \& Ortolani E.L. 2012. Copper deficiency in sheep with high liver iron accumulation. Vet. Med. Int. 2012, art. 207950, p.1-4.

Suttle N.F. 2010. Mineral Nutrition of Livestock. 4th ed. CABI Publishing, Oxfordshire. 587p.

Tebaldi F.L.H., Silva J.F.C., Vasquez H.M. \& Thiebaut J.T.L. 2000. Composição mineral das pastagens das regiões norte e noroeste do Estado do Rio de Janeiro. 2. Manganês, ferro, zinco, cobre, cobalto, molibdênio e chumbo. Revta Bras. Zootec. 29(2):616-629.

Tokarnia C.H., Döbereiner J., Canella C.F.C. \& Guimarães J.A. 1966. Ataxia enzoótica em cordeiros no Piauí. Pesq. Agropec. Bras. 1:375-382.

Tokarnia C.H., Döbereiner J. \& Moraes S.S. 1988. Situação atual e perspectivas da investigação sobre nutrição mineral em bovinos no Brasil. Pesq. Vet. Bras. 8(1/2):1-16.

Tokarnia C.H., Döbereiner J. \& Peixoto P.V. 2000. Deficiências minerais em animais de fazenda, principalmente bovinos. Pesq. Vet. Bras. 20(3):127138.

Van Niekerk F.E., Cloete S.W.P., Barnard S.A. \& Heine E.W.P. 1990. Plasma copper, zinc and blood selenium concentrations of sheep, goats and cattle. S. Afr. J. Anim. Sci. 20(3):144-147.

Van Ryssen J.B. \& Stielau W.J. 1981. Effect of different levels of dietary molybdenum on copper and Mo metabolism in sheep fed on high levels of Cu. Brit. J. Nutr. 45:203-210. 